\title{
Conditions in utero and cancer risk
}

\author{
S. Tretli ${ }^{1,2}$, E. Weiderpass ${ }^{1,3}$ and T. Grotmol ${ }^{1}$ \\ 1) Division of Aetiological Research, The Cancer Registry of Norway, Oslo \\ 2) Department of Community Medicine and General Practice, The Norwegian University of Science \\ and Technology, Trondheim \\ 3) Department of Medical Epidemiology and Biostatistics, Karolinska Institutet, Stockholm \\ Correspondence: Steinar Tretli, Kreftregisteret, Montebello, 0310 Oslo \\ E-mail: steinar.tretli@kreftregisteret.no Telephone:+4722451300 Telefax: +47 22451370
}

\section{INTRODUCTION}

Most cancer cases are diagnosed after the age of 60 . Over the past years, however, increasing evidence has supported the notion that conditions in utero or early childhood may be of importance for the disease process. Such hypotheses have been examined and discussed for other chronic diseases, ${ }^{1}$ and in fact also for specific types of cancer. ${ }^{2}$ Already in 1877 , the German pathologist Julius Cohnheim hypothesised that events in utero could be related to cancer later in life, and he pinpointed the similarity between the cancer cells and embryonic cells. ${ }^{3}$

Based on historical analysis of infant mortality in two municipalities in Norway in 1814-78, Fure ${ }^{4}$ suggested that mothers themselves born in socio-economic prosperous times, gave birth to children with a lower rate of neonatal deaths than those of mothers born under less favourable conditions. This study emphasises the possibility that exposures in utero in one generation may influence the vitality even in later generations. By the same token, in a Swedish cohort of individuals born in 1928 the relation between parental economic resources and mortality among elderly was studied. ${ }^{5}$ The rich information on individual income throughout the entire life cycle allowed the researchers to construct a measure of lifetime earnings. A competing risk analysis showed a strong relation between parental income and death from cancer while own income later in life seemed more important for circulatory diseases as cause of death.

In 2001, the median age for all cancer types in Norway was 70 years for men and 69 years for women. Nine percent of the male and $14 \%$ of the female cases were diagnosed before age 50 , and only $2 \%$ were diagnosed before age 30 for both genders. ${ }^{6}$ Although inherited gene alterations are expected to be more prevalent in younger than older cases, it is notable that even the young cases have lived for a long time exposed to a variety of possibly harmful factors before the cancer is diagnosed. Another observation further emphasising the length of the disease process, comes from migration studies, which indicate that adoption of the cancer rates in the first generation depends on the age at migration. ${ }^{7}$

Cancer is generally believed to arise from a single cell and is initiated when the cell has experienced at least two genetic alterations, although other theories exist. ${ }^{8}$ The critical genes are basically oncogenes, tumour suppressor genes and DNA repair genes. In the case of retinoblastoma, Knudson ${ }^{9}$ suggested that gene alterations affecting both alleles of the same gene (designated $\mathrm{Rb}$ ) were necessary to initiate cancer. In colon cancer, a similar initiation seems to be necessary, but seven or eight gene alterations are probably needed. ${ }^{10}$ It is not known if these alterations demand a special order of sequence. This indicates that it takes time to accumulate enough genetic damage ${ }^{11}$ and to develop a detectable cancer. Even for lung cancer where smoking is an established strong causal factor, the median age at diagnosis is 69 years. Only a minor proportion of the heavy smokers develop lung cancer during their lifetime, ${ }^{12}$ indicating an individual susceptibility for cancer. This susceptibility may be inherited $^{13}$ or acquired in utero or in early life when the organs are still developing. The biological mechanisms behind heterogeneous susceptibility and the relation to environmental and lifestyle factors are not well understood. Hypothetically they have been linked to factors influencing the number of cells at risk, events that may cause genetic instability, increased risk of essential mutations during the development of target organs, or a gene-environment interaction during intrauterine life. ${ }^{14}$ These hypotheses are not mutually exclusive.

After the initiation of the first cancer cell, the tumour has to grow to a detectable size before it could be diagnosed. A tumour that has doubled its size 30 times, will be about $1 \mathrm{~cm}^{3}$. Depending on the type of cancer, the tumour size will usually double a few more times before giving rise to clinical symptoms. The growth rate depends on the frequencies of mitosis and apoptosis, but also on the rate of angiogenesis. These important events in the disease process can also hypothetically be linked to conditions in utero, but to our knowledge, studies have not been undertaken to shed light on these issues.

The in utero hypothesis implies that the disease process in a broad sense may last several decades, which makes it difficult to design relevant epidemiological studies. Data on exposures and conditions in utero way back in time are obviously limited, and therefore most of the evidence for an association 
between in utero exposures and cancer risk is based on indirect observations. Below, we summarise the evidence regarding the association between intrauterine exposure and testicular and breast cancer, the two cancer sites most studied so far in this regard. In addition, epidemiological findings for other types of cancer are addressed in a more general manner.

\section{TESTICULAR CANCER (TC)}

The incidence rate of TC in Caucasian men in at least Europe and North America, has increased several fold over the past 50 years. ${ }^{15,16}$ Few other cancer forms have shown a similar rise in incidence rate during this period, and this rapid change within a couple of generations suggests that exogenous rather than genetic factors should be considered. Several epidemiological features of TC suggest that the disease originates early in life. First, TC incidence rate peaks between 25 and 35 years of age. ${ }^{6}$ Second, migrant studies have shown that immigrants keep the risk of TC of their native population. ${ }^{17}$ Third, year of birth is a more important risk determinant than calendar year of diagnosis. ${ }^{18}$ Fourth, TC incidence is associated with conditions pertaining to pregnancy. ${ }^{19}$ Fifth, TC, hypospadias (incomplete closure of the urethral fold), cryptorchidism (undescended testis), and low sperm quality are thought to be symptoms of one underlying entity, the testicular dysgenesis syndrome (TDS), with a common origin in foetal life. ${ }^{20}$ In the following, these issues are further described, and a brief outline of the proposed mechanisms being involved in the development of $\mathrm{TC}$ is given.

\section{Epidemiological features}

Cancer usually takes decades to develop, and cancer types with an early age peak are generally regarded as having been initiated early in life and even in utero. Similar inference can be made from migrant studies showing that men moving from a low TC risk area (e.g. Finland) to a high risk area (e.g. Sweden), kept their low risk comparable to those who were still living in Finland. ${ }^{17}$

Several age-period-cohort and frailty modelling studies have independently shown that men born in Sweden, Denmark and Norway during World War II (WWII) have a lower TC incidence than men born in the years before or after WWII. ${ }^{18,21,22}$ The underlying mechanisms are still elusive, but most likely relate to the caloric restriction of $5-20 \%$ that took place in the Scandinavian countries during the war, since such conditions have been shown to reduce cancer incidence in experimental animals. ${ }^{23}$ On the other hand, one cannot exclude an association between TC risk and reduced intake of harmful nutritional components or vice versa during WWII. ${ }^{24}$ Maternal smoking during pregnancy has been proposed as a causal factor for TC in the offspring. ${ }^{25}$ The daily consumption of tobacco decreased during the war ${ }^{26}$ and thus compatible with a reduced risk in the offspring in this period. The overall potential effect of this alteration in maternal smoking, however, was most likely limited, given the low prevalence of female smokers at that time. ${ }^{26}$

\section{Testicular dysgenesis syndrome (TDS)}

TDS is thought to have increased in most Western countries over the past decades. These conditions (TC, hypospadias, cryptorchidism, and poor semen quality) share several risk factors and often coincide in affected individuals. The aetiology of the clinical components of TDS syndrome remains unknown in the majority of cases, but is believed to be multi-factorial, involving both genetic and environmental factors, which disturb the gonadal development in utero. ${ }^{20}$

The origin of TC (with the exception of spermatocytic seminoma) is believed to be carcinoma in situ cells, whose malignant transformation is initiated during the early development from primordial germ cells or gonocytes that fail to end proliferation or undergo proper differentiation. ${ }^{27,28}$ The first trimester of pregnancy is therefore considered most critical for the development of TC.

\section{Conditions pertaining to pregnancy}

Case-control studies have shown that various maternal factors related to pregnancy are associated with increased risk of TC in the offspring. These factors include infection of the urinary system, retained placenta, and low birth weight. ${ }^{19,29}$ In light of the proposed 'oestrogen hypothesis' (see below), a special interest is connected to an elevated risk of TC in boys born in their mothers' first pregnancy. Then the maternal level of bioavailable oestrogen is higher than in subsequent pregnancies due to less sex-hormone binding globulin (SHBG) in nulliparous women. The risk of TC tends to be higher in dizygotic than monozygotic twins, an observation which has also been associated with the higher levels of oestrogen during dizygotic pregnancies. Although, only some of these risk factors have a well-defined relationship with oestrogen, the mere presence of risk factors related to pregnancy underscores the importance of this period.

\section{The oestrogen hypothesis}

Over the past decades, there has been concern about a possible adverse trend in male reproduction due to increasing incidence of testicular cancer, ${ }^{15,16}$ and possibly also hypospadias and cryptorchidism ${ }^{30,31}$ as well as an apparent decrease in semen quality. ${ }^{32}$ In 1993, Sharpe and Skakkebæk launched the so-called 'oestrogen hypothesis', suggesting that increased exposure to endogenous or exogenous estrogens in utero could be a cause of these disorders of the male reproductive tract. $^{33}$ Increased exposure to oestrogens early in foetal life may have adverse effect on both Sertoli and 
Leydig cells, and thus also on germ cells, and can potentially lead to increased risk of these disorders.

Exposure of pregnant mice to oestrogens has been found to increase the frequency of testicular dysgene$\mathrm{sis}^{34}$, cryptorchidism ${ }^{35}$, hypospadias ${ }^{36}$ and $\mathrm{TC}^{37}$ in male offspring; and there is also evidence of impaired Leydig cell development and reduced Sertoli cell numbers, resulting in impaired spermatogenesis. ${ }^{34}$ The same associations have been suggested in humans, ${ }^{38}$ although they are still under debate. ${ }^{39}$ Sons of women who themselves were exposed in utero to diethylstilbestrol (DES), may have an elevated risk of TC although the data are not unequivocal. ${ }^{40}$

The most straightforward way by which the foetus could be exposed to high levels of oestrogens, is through increased bioavailability of maternal high oestradiol levels naturally occurring during pregnancy. ${ }^{39}$ Bioavailability of oestradiol is mainly regulated by the level of SHBG, whose most important endogenous suppressor is insulin. It has recently been shown that the maternal weight dropped transiently in Norway during WWII, when the population was exposed to energy restriction (15-20\%), and by inference, reduced insulin levels. ${ }^{41}$ There was a correlation between maternal weight and the risk of TC for those who were born in the study period 1931-55. Given the mechanism outlined above, the insulin level could thus represent a link between increased body mass in most populations during recent decades and the corresponding increased incidence of TC.

Since 1993, the oestrogen hypothesis has been expanded to include also environmental antiandrogens with potential adverse effects on male reproductive health. ${ }^{20,38}$ By blocking androgen action, exposure to an antiandrogen may cause changes similar to those associated with oestrogen exposure, and in addition, several environmental oestrogen receptor agonists are also androgen receptor antagonists. ${ }^{42}$ Male animals exposed to antiandrogens in utero have been found to develop cryptorchidism, hypospadias, infertility, and testis abnormalities similar to those seen in human TDS. $^{43-45}$ Thus, according to the latest version of the oestrogen hypothesis, increased exposure to oestrogenic and antiandrogenic endocrine disrupters, or an otherwise change in the androgen-oestrogen balance in utero, can lead to disruption of embryonal programming and gonadal development, resulting in more or less grave symptoms of TDS..$^{20,33,39}$ It has been suggested that it is the balance between oestrogens and androgens that is important, rather than the relative levels, regarding the risk of TDS. ${ }^{39}$

In summary, although TC is a disease where the evidence in favour of an in utero onset is reasonably persuasive, the mechanisms are still elusive. This review has focused mainly on factors acting in utero. In addition, there is a genetic component in the aetiology of this cancer form, since a family history of TC in a first-degree relative is a consistent risk factor. Based on recent years' research, there is reason to believe that studies taking advantage of the concept of TDS, are most likely to provide the most interesting results regarding the aetiology of $\mathrm{TC}$, both in terms of genetic and environmental factors.

\section{BREAST CANCER (BC)}

The median age at diagnosis of BC in Norway before the implementation of mammography screening programmes was 64 years. ${ }^{46}$ Studies among young women treated with radiation for Hodgkin disease as well as on BC incidence among atomic bomb survivors strongly indicate the importance of early life exposure for BC development. ${ }^{47}$ In 1990, Trichopoulos proposed that $\mathrm{BC}$ might originate already in utero. ${ }^{48}$ Both previous and recent studies have given support to this statement. First, migrant studies indicate that the age at migration is related to the acquisition of $\mathrm{BC}$ risk from the host country. Second, BC incidence is associated with conditions pertaining to pregnancy, such as preeclampsia. Third, BC is associated with birth weight. Fourth, animal studies support the importance of conditions in utero.

\section{Migrant studies}

Migrant studies have evidenced that adaptation of BC rates in the first generation depends on age at migration. Adaptation is more evident in the second generation migrants. Particularly if the women move at very young age, they adopt the BC rates in the host country. ${ }^{49,50}$ This indicates a clear effect of factors acting early in life other than genetical susceptibility in $\mathrm{BC}$ aetiology.

\section{Conditions pertaining to pregnancy}

There is some evidence that women who are firstborn have an increased risk of $\mathrm{BC}$, and a higher risk is seen among dizygotic than monozygotic twins. ${ }^{51}$ The supposed mechanisms are associated with higher oestrogen levels as discussed for TC above. Studies conducted in Sweden with information abstracted from patients' medical records, indicate that the offspring of mothers who had pre-eclampsia, have a substantially reduced $\mathrm{BC}$ risk later in life. ${ }^{14} \mathrm{~A}$ study by Sanderson et al. ${ }^{52}$ supported this observation based on self-reports from the mothers. A large study conducted in Norway, found a $20 \%$ decreased pre- and post-menopausal BC risk among daughters of women with pre-eclampsia and or hypertension during pregnancy. These results were consistent both in term and pre-term deliveries, and across different birth weights. ${ }^{53}$ The mechanism involved may include lower levels of foetal oestrogen exposure, which characterises pregnancies with preeclampsia. There is some evidence that the antioestrogenic effect associated with pre-eclampsia may be mediated through high levels of alpha-foetoprotein rather than low levels of oestradiol. ${ }^{54}$

Maternal age at time of birth has been associated 
with $\mathrm{BC}$ risk in the daughters in some studies. ${ }^{51}$ Oestrogen levels may be higher in older pregnant women, although results on hormonal levels relative to age have been inconsistent. Some further studies are warranted to clarify this area.

Length of gestation has been inconsistently associated with a higher risk of $\mathrm{BC} .^{52,55-58} \mathrm{We}$ could not identify epidemiological studies in humans suggesting clear effects of maternal diet and BC risk in the daughters. Findings in animal studies, however, suggest that increased exposure to oestradiol in foetal life and adolescence, significantly affects $\mathrm{BC}$ risk, ${ }^{59}$ indicating that the time of exposure of the breast to oestradiol is of importance for carcinogenesis in this organ. Elevated birth weight due to obesity induced in the mothers has also been shown to affect both the incidence and the number of breast tumours per animal. Maternal exposure to a high fat diet and alcohol, increases pregnancy oestrogen levels, and moderate alcohol intake during pregnancy increases $\mathrm{BC}$ risk in the offspring. ${ }^{60}$ Studies in mice have demonstrated that $\mathrm{BC}$ risk can be manipulated by diet during pregnancy and adolescence. Thus, dietary factors during pregnancy associated with a reduced $\mathrm{BC}$ risk in the offspring, were whole wheat diet (very rich in fibre), and low fat fish oil. The corresponding dietary factors increasing $\mathrm{BC}$ risk in the offspring were genistein, alcohol, fat diet, including high fat fish oil, and fibre from flaxid. Interestingly, while a pregnancy diet rich in genistein reduced risk of $\mathrm{BC}$, a similar diet administered during puberty increase risk, ${ }^{61}$ indicating that the timing of dietary exposure may produce different effects in terms of $\mathrm{BC}$ risk.

\section{Anthropometric measurements at birth}

Most studies looking at early life events in relation to $\mathrm{BC}$ risk, have been dealing with birth weight, as a proxy for foetal growth rate and gestational duration, in addition to possibly other as yet unidentified foetal exposures. Birth weight is also influenced by genetical factors, maternal pre-pregnancy weight, weight gain during pregnancy, maternal diet during pregnancy, and pregnancy hormone levels (insulin-like growth factor 1 and 2, oestrogen, and leptin, among others). There are at least 20 published studies on birth weight as determinant of BC risk, most of them ${ }^{14,53,57,58,62-74}$ indicating that birth weight is positively associated with $\mathrm{BC}$ risk. While the evidence of a positive association between birth weight and premenopausal $\mathrm{BC}$ is quite convincing, the data for post-menopausal $\mathrm{BC}$ are less consistent. $^{51}$

Besides birth weight, birth length is of interest. McCormack et al. ${ }^{68}$ found that the effect of birth weight disappeared after adjustment for birth length or head circumference, whereas the effects of birth length and head circumference remained significant after adjustment for birth weight. Few studies have been published in this area, and more information is warranted. In a Norwegian study, the odds ratio for women who were in the highest quartile of birth length was increased compared with those being in the lowest quartile. ${ }^{64}$

Other childhood and adolescent characteristics such as high stature in adolescence, and peak growth at an early age have been convincingly associated with $\mathrm{BC}$ risk, and they seem to interact with birth weight. ${ }^{63}$

\section{OTHER TYPES OF CANCER}

Anthropometric measurements at birth have been linked to several types of cancer. These studies have been performed as a result of the findings in the BC studies, but also because birth weight and length are the only quality data from the intrauterine period available for studies of adult cancer. The other focus on exposures during intrauterine life is rooted in the difficulties in obtaining specific exposure data far back in time. These difficulties imply that studies can mainly be conducted for childhood cancer. Thus, care must be taken when making inferences from the results, due to the differences that often exist between cancer in childhood and adulthood, which may reduce the general applicability of the results. The childhood cancer studies are usually retrospective and hence highly vulnerable for selection bias. In addition, it is difficult to state if an exposure has been specific to the in utero period only, and the studies often include a small number of cases. In the following, a short summary of the birth weight studies and the childhood cancer studies are presented.

\section{Birth weight}

Eight studies examining the association between birth length and weight and prostate cancer, have revealed inconsistent results. In the five studies that did not show any association, ${ }^{62,75-78}$ the number of cases varied between 192 and 834. Nilsen et al. found an association with birth length and metastatic prostate cancer, but not for all stages of prostate cancer combined. ${ }^{79}$ Tiblin et al. found a significant association with high birth weight, but the study was based on only 21 cases. ${ }^{80}$ In a Danish study ${ }^{81}$, a significant positive association was seen among those with birth weight more than $3500 \mathrm{~g}$, but the study comprised only 56 individuals.

Bergstrom et al. found a weak association with kidney cancer when comparing those with birth weight above $3500 \mathrm{~g}$ with $3000-3499 \mathrm{~g}$, but only in males. ${ }^{82}$ Ahlgren et al. found a tendency to increased incidence by increasing birth weight, both for kidney and bladder cancer. $^{81}$ The association was found only in birth weight groups below $3500 \mathrm{~g}$ for kidney cancer and above $3500 \mathrm{~g}$ for bladder cancer. In a recent study, however, no association was found between birth weight and malignant neoplasm in the urinary system. $^{62}$

Several studies have shown an elevated risk of Wilms' tumour among children with a high birth 
weight, and it is suggested that the association is restricted mainly to children aged less than 2 years at diagnosis. The largest study with 1800 cases pinpointed the heterogeneity in the pathogenesis of Wilms' tumour, and that the strength of the association was different for the various sub-types. ${ }^{83}$

Sandhu et al. suggested a J-shaped relation between self-reported birth weight and colorectal cancer. ${ }^{84}$ Babies born with macrosomia appear to have the greatest risk. However, the study was based on 52 cases only. A larger study ${ }^{62}$ showed a $16 \%$ elevated risk per one standard deviation increase in birth weight while a third study ${ }^{81}$ found no association between birth weight and colorectal cancer.

McCormack et al. found a reduced risk by increasing birth weight among 112 cases of endometrial cancer, ${ }^{62}$ whereas Ahlgren et al. could not demonstrate any association neither for endometrial, cervix nor ovary cancer. ${ }^{81}$ Both these studies ${ }^{81,62}$ demonstrated an increased (but non-significant) risk of pancreatic cancer by increasing birth weight. Furthermore, in the Danish study a significant positive association was seen between birth weight and lung cancer, ${ }^{81}$ while a positive trend of borderline significance for cancer in the respiratory system was observed in the study by McCormack et al. ${ }^{62}$

The results for malignant melanoma have been inconsistent. ${ }^{62,81}$ McCormack et al. found a significant positive association between birth weight and cancer in the lymphatic and haematopoietic tissue in adult persons, and a similar tendency was seen for multiple myeloma and Non-Hodgkin lymphoma. A metaanalysis of more than 10000 children concluded with an increased risk of acute lymphoblastic leukaemia for those with a birth weight of more than $4000 \mathrm{~g}$ compared with weight less than $4000 \mathrm{~g} .{ }^{85}$ These results have been confirmed in a recent Nordic study. ${ }^{86}$

Neither McCormack et al. ${ }^{62}$ nor Ahlgren et al. ${ }^{81}$ could find any association between birth weight and cancer in the brain or the nervous system in adult persons. However, a relationship has been shown between high birth weight (more than $4000 \mathrm{~g}$ ) and the incidence of astrocytoma. ${ }^{87}$

A significant positive association between birth weight and all types of cancer combined is seen for males and for females under age of 50 years. ${ }^{62}$ The demonstrated association found for $\mathrm{BC}$ in premenopausal women dominated the association for cancer combined for women under 50 years. In the Danish study, a positive association between birth weight and all types of cancer combined was seen both for men and women. ${ }^{81}$

\section{Other exposures during intrauterine life}

In 1999, Little ${ }^{87}$ published an extensive review of childhood cancer, the most frequent types being leukaemia, brain tumours and lymphoma. According to the review, exposure to diagnostic X-rays in utero is associated with leukaemia, whereas paternal occupational exposure to solvents, paternal smoking and maternal alcohol consumption during pregnancy are classified as associated with some degree of consistency with leukaemia. For lymphoma, no factor in utero has been found to be consistently associated. For brain tumours, exposure to diagnostic X-rays in utero is classified as associated. Maternal consumption of cured meats during index pregnancy, maternal use of vitamin supplements during early pregnancy and high birth weight (astrocytoma) have been classified as associated with some degree of consistency. ${ }^{87}$

Among the less frequent types of childhood cancer, maternal use of sex hormones before or during pregnancy has been associated with some degree of consistency with neuroblastoma. Regarding Wilms' tumour, a similar classification exists for high birth weight and paternal employment in occupations potentially involving exposure to metals. ${ }^{87}$

\section{Comments}

The overwhelming problem in testing the in utero hypothesis is the difficulty of getting relevant exposure data from the in utero period. Birth weight and length have been registered carefully for a long time, and that is likely the main reason for all the studies carried out on birth weight and cancer later in life. However, a feeling remains that the proverbial "lamppost has been successfully moved to the place where the keys were lost", applies. On the other hand, an association between birth weight and a cancer form indicates that something related to the birth weight is a potential causal factor for the cancer form in question.

So far, the results have indicated that the hormonal conditions during pregnancy may be of importance. Another issue is whether birth weight can be related to number of cells at risk in the organ. The old multistage models assume that a set of tissue cells serve as the basis for all the events that take place before a cancer is detected. The risk depends on the number of cells in this set. It has been calculated that about 42 rounds of cell divisions in the fertilised human ovum occur before birth and only a further five division after birth. ${ }^{88}$ It is rather well documented that adult height is a risk factor for breast ${ }^{89}$ and colo-rectal cancer ${ }^{90}$, but also for malignant melanoma ${ }^{91}$, and uterine corpus cancer ${ }^{92}$. These observations have been linked to the number of cell under risk for acquiring cancer. ${ }^{82,93,94}$ Recently, Ballen et al. ${ }^{95}$ have shown that foetal growth reflects the number of primitive proliferating cells in umbilical cord blood which may be an indication of the susceptibility to cancer. ${ }^{96}$

Knowledge about specific exposures in utero and cancer is almost absent. However, the association between radiation exposure in utero and cancer ${ }^{97}$ and between use of $\mathrm{DES}^{40}$ and cancer, may illustrate the need for more information and hopefully from pros- 
pective studies. For most types of cancer, specific exposures in adult life are better documented as risk factors for cancer. The frailty model for $\mathrm{TC}^{98}$ indicates that the proportion of frail men increases over birth cohorts. This could happen if the frailty arises through a gene-environment interaction during intrauterine life. Different adult exposures may modify the disease process among the frail persons, providing an array of variation in time delay until the cancer is diagnosed. Some frail individuals may even die from other causes before this occurs. While limited knowledge exists about adult risk factors for TC, the situation is somewhat different for $\mathrm{BC}$ and some other types of cancer. In lung cancer development, frailty most likely play a role, but smoking habits are of decisive importance.

The foetal life is critical for the development of the different organs and conditions in utero seem to influence not only cancer, but also other types of diseases later in life. This calls for increased focus on pregnancy as a potential disease preventive phase of life.
However, as of today, we should apply with care the limited knowledge about exposures in utero in cancer prevention.

A problem in epidemiology is the huge number of association studies carried out in adult populations to examine the importance of different environmental or lifestyle factors for cancer incidence. Mainly factors measured close to the time of diagnosis are considered. Individual hereditary conditions or acquired susceptibility for cancer in utero make an interesting background for reviewing and interpreting previously conducted studies and in the planning of new studies. The accumulating evidence of the conditions in utero being relevant for the origin of some cancer forms, ought to stimulate experimental studies aimed at testing specific hypotheses to a larger extent than what has been done so far. However, it has been claimed that it is too limited to focus solely on the situation in utero, and that conditions in early life should be included, but this was beyond the scope of this review.

\section{REFERENCES}

1. Barker DJP. Mothers, babies and health in later life. Churchill Livingstone, Edinburgh, 1988.

2. Kuh D, Ben-Shlomo Y. A life course approach to chronic disease epidemiology. Oxford Press, Oxford, 2004.

3. Gade FG. Kreftsykdommene. Deres vesen, utbredelse og bekjempelse. Steenske forlag, Oslo, 1929.

4. Fure E.: ...en besynderlig Regelmæssighet. Dødeligheten i Asker og Bærum på 1800 -tallet med særlig vekt på spebarnsdødeligheten. Det historisk-filosofiske fakultet, Universitetet i Oslo, 2004 (Doctoral Thesis).

5. Palme M, Sandgren S. Parental income, lifetime income and mortality. http://people.su.se/ palme/, 2005.

6. Cancer Registry of Norway. Cancer in Norway 2001. Info Print A/S, Oslo, 2004.

7. Tomatis L, ed. Cancer: Causes, occurrence and control. IARC Scientific Publication No, 100, Lyon, 1990.

8. Soto AM, Sonnenschein C. The somatic mutation theory of cancer: growing problems with the paradigm? Bioessays 2004; 26: 1097-107.

9. Knudson AG, Jr. Mutation and cancer: statistical study of retinoblastoma. Proc Natl Acad Sci USA 1971; 68: 820-3.

10. Fodde R, Smits R, Clevers H. APC, signal transduction and genetic instability in colorectal cancer. Nat Rev Cancer 2001; 1: 55-67.

11. Stein WD. Analysis of cancer incidence data on the basis of multistage and clonal growth models. Adv Cancer Res 1991; 56: 161-213.

12. Halpern MT, Gillespie BW, Warner KE. Patterns of absolute risk of lung cancer mortality in former smokers. J Natl Cancer Inst 1993; 85: 457-64.

13. Sellers TA, Bailey-Wilson JE. Familial predisposition to lung cancer. In: Roth JA, Hong WK, eds. Lung cance. Blackwell, Malden, MA, 1998: 57-71.

14. Ekbom A, Trichopoulos D, Adami HO, Hsieh CC, Lan SJ. Evidence of prenatal influences on breast cancer risk. Lancet 1992; 340: 1015-8.

15. Huyghe E, Matsuda T, Thonneau P. Increasing incidence of testicular cancer worldwide: a review. $J$ Urol 2003; 170: 5-11.

16. Richiardi L, Bellocco R, Adami HO, Torrang A, Barlow L, Hakulinen T, et al. Testicular cancer incidence in eight northern European countries: secular and recent trends. Cancer Epidemiol Biomarkers Prev 2004; 13: 2157-66.

17. Ekbom A, Richiardi L, Akre O, Montgomery SM, Sparen P. Age at immigration and duration of stay in relation to risk for testicular cancer among Finnish immigrants in Sweden. J Natl Cancer Inst 2003; 95: 1238-40.

18. Bergstrom R, Adami HO, Mohner M, Zatonski W, Storm H, Ekbom A, et al. Increase in testicular cancer incidence in six European countries: a birth cohort phenomenon. J Natl Cancer Inst 1996; 88: 727-33.

19. Wanderas EH, Grotmol T, Fossa SD, Tretli S. Maternal health and pre- and perinatal characteristics in the etiology of testicular cancer: a prospective population- and register-based study on Norwegian males born between 1967 and 1995. Cancer Causes Control 1998; 9: 475-86. 
20. Skakkebaek NE, Rajpert-De Meyts E, Main KM. Testicular dysgenesis syndrome: an increasingly common developmental disorder with environmental aspects. Hum Reprod 2001; 16: 972-8.

21. Moller H. Decreased testicular cancer risk in men born in wartime. J Natl Cancer Inst 1989; 81: 1668-9.

22. Wanderas EH, Tretli S, Fossa SD. Trends in incidence of testicular cancer in Norway 1955-1992. Eur J Cancer 1995; 31A: 2044-8.

23. Hursting SD, Lavigne JA, Berrigan D, Perkins SN, Barrett JC. Calorie restriction, aging, and cancer prevention: mechanisms of action and applicability to humans. Annu Rev Med 2003; 54: 131-52.

24. Angell-Andersen E, Tretli S, Bjerknes R, Forsen T, Sorensen TI, Eriksson JG, et al. The association between nutritional conditions during World War II and childhood anthropometric variables in the Nordic countries. Ann Hum Biol 2004; 31: 342-55.

25. Clemmesen J. Is pregnancy smoking causal to testis cancer in sons? A hypothesis. Acta Oncol 1997; 36: 5963.

26. Ronneberg A, Lund KE, Hafstad A. Lifetime smoking habits among Norwegian men and women born between 1890 and 1974. Int J Epidemiol 1994; 23: 267-76.

27. Rajpert-De Meyts E, Jorgensen N, Brondum-Nielsen K, Muller J, Skakkebaek NE. Developmental arrest of germ cells in the pathogenesis of germ cell neoplasia. APMIS 1998; 106: 198-204.

28. Skakkebaek NE, Berthelsen JG, Giwercman A, Muller J. Carcinoma-in-situ of the testis: possible origin from gonocytes and precursor of all types of germ cell tumours except spermatocytoma. Int J Androl 1987; 10: 1928.

29. Depue RH, Pike MC, Henderson BE. Estrogen exposure during gestation and risk of testicular cancer. $J$ Natl Cancer Inst 1983; 71: 1151-5.

30. Paulozzi LJ. International trends in rates of hypospadias and cryptorchidism. Environ Health Perspect 1999; 107: 297-302.

31. Toppari J, Kaleva M, Virtanen HE. Trends in the incidence of cryptorchidism and hypospadias, and methodological limitations of registry-based data. Hum Reprod Update 2001; 7: 282-6.

32. Swan SH, Elkin EP, Fenster L. The question of declining sperm density revisited: an analysis of 101 studies published 1934-1996. Environ Health Perspect 2000; 108: 961-6.

33. Sharpe RM, Skakkebaek NE. Are oestrogens involved in falling sperm counts and disorders of the male reproductive tract? Lancet 1993; 341: 1392-5.

34. Yasuda Y, Kihara T, Tanimura T, Nishimura H. Gonadal dysgenesis induced by prenatal exposure to ethinyl estradiol in mice. Teratology 1985; 32: 219-27.

35. Walker AH, Bernstein L, Warren DW, Warner NE, Zheng X, Henderson BE. The effect of in utero ethinyl oestradiol exposure on the risk of cryptorchid testis and testicular teratoma in mice. Br J Cancer 1990; 62: 599-602.

36. Kim KS, Torres CR, Jr, Yucel S, Raimondo K, Cunha GR, Baskin LS. Induction of hypospadias in a murine model by maternal exposure to synthetic estrogens. Environ Res 2004; 94: 267-75.

37. Newbold RR, Bullock BC, McLachlan JA. Testicular tumors in mice exposed in utero to diethylstilbestrol. $J$ Urol 1987; 138: 1446-50.

38. Toppari J, Larsen JC, Christiansen P, Giwercman A, Grandjean P, Guillette LJ, et al. Male reproductive health and environmental xenoestrogens. Environ Health Perspect 1996; 104 (Suppl 4): 741-803.

39. Sharpe RM. The 'oestrogen hypothesis' - where do we stand now? Int J Androl 2003; 26: 2-15.

40. Strohsnitter WC, Noller KL, Hoover RN, Robboy SJ, Palmer JR, Titus-Ernstoff L, et al. Cancer risk in men exposed in utero to diethylstilbestrol. J Natl Cancer Inst 2001; 93: 545-51.

41. Aschim EL, Grotmol T, Tretli S, Haugen TB. Is there an association between maternal weight and the risk of testicular cancer? An epidemiologic study of Norwegian data with emphasis on World War II. Int J Cancer 2005; 116: 327-330.

42. Sohoni P, Sumpter JP. Several environmental oestrogens are also anti-androgens. J Endocrinol 1998; 158: 327-39.

43. Gray LE, Jr., Ostby J, Monosson E, Kelce WR. Environmental antiandrogens: Low doses of the fungicide vinclozolin alter sexual differentiation of the male rat. Toxicol Ind Health 1999; 15: 48-64.

44. McIntyre BS, Barlow NJ, Foster PM. Androgen-mediated development in male rat offspring exposed to flutamide in utero: Permanence and correlation of early postnatal changes in anogenital distance and nipple retention with malformations in androgen-dependent tissues. Toxicol Sci 2001; 62: 236-49.

45. Fisher JS, Macpherson S, Marchetti N, Sharpe RM. Human 'testicular dysgenesis syndrome': A possible model using in-utero exposure of the rat to dibutyl phthalate. Hum Reprod 2003; 18: 1383-94.

46. Engeland A, Haldorsen T, Tretli S, Hakulinen T, Horte LG, Luostarinen T, et al. Prediction of cancer incidence in the Nordic countries up to the years 2000 and 2010. A collaborative study of the five Nordic Cancer Registries. APMIS Suppl 1993; 38: 1-124. 
47. Land CE, Tokunaga M, Koyama K, Soda M, Preston DL, Nishimori I, et al. Incidence of female breast cancer among atomic bomb survivors, Hiroshima and Nagasaki, 1950-1990. Radiat Res 2003; 160: 707-17.

48. Trichopoulos D. Hypothesis: does breast cancer originate in utero? Lancet 1990; 335: 939-40.

49. Tominaga S. Cancer incidence in Japanese in Japan, Hawaii, and western United States. Natl Cancer Inst Monogr 1985; 69: 83-92.

50. Ziegler RG, Hoover RN, Pike MC, Hildesheim A, Nomura AM, West DW, et al. Migration patterns and breast cancer risk in Asian-American women. J Natl Cancer Inst 1993; 85: 1819-27.

51. Potischman N, Troisi R, Vatten L. A life course approach to cancer epidemiology. In: Kuh D, Ben-Shlomo Y, eds. A life course approach to chronic disease epidemiology. Oxford Press, Oxford, 2004.

52. Sanderson M, Williams MA, White E, Daling JR, Holt VL, Malone KE, et al. Validity and reliability of subject and mother reporting of perinatal factors. Am J Epidemiol 1998; 147: 136-40.

53. Vatten LJ, Maehle BO, Lund Nilsen TI, Tretli S, Hsieh CC, Trichopoulos D, et al. Birth weight as a predictor of breast cancer: a case-control study in Norway. Br J Cancer 2002; 86: 89-91.

54. Vatten LJ, Romundstad PR, Odegard RA, Nilsen ST, Trichopoulos D, Austgulen R. Alpha-foetoprotein in umbilical cord in relation to severe pre-eclampsia, birth weight and future breast cancer risk. $\mathrm{Br} \mathrm{J} \mathrm{Cancer}$ 2002: 86: 728-31.

55. Le Marchand L, Kolonel LN, Myers BC, Mi MP. Birth characteristics of premenopausal women with breast cancer. Br J Cancer 1988; 57: 437-52.

56. Sanderson M, Williams MA, Malone KE, Stanford JL, Emanuel I, White E, et al. Perinatal factors and risk of breast cancer. Epidemiology 1996; 7: 34-7.

57. Michels KB, Trichopoulos D, Robins JM, Rosner BA, Manson JE, Hunter DJ, et al. Birthweight as a risk factor for breast cancer. Lancet 1996; 348: 1542-6.

58. Ekbom A, Erlandsson G, Hsieh C, Trichopoulos D, Adami HO, Cnattingius S. Risk of breast cancer in prematurely born women. J Natl Cancer Inst 2000; 92: 840-1.

59. Hilakivi-Clarke L, Wang C, Kalil M, Riggins R, Pestell RG. Nutritional modulation of the cell cycle and breast cancer. Endocr Relat Cancer 2004; 11: 603-22.

60. Hilakivi-Clarke L, Clarke R, Onojafe I, Raygada M, Cho E, Lippman M. A maternal diet high in n -6 polyunsaturated fats alters mammary gland development, puberty onset, and breast cancer risk among female rat offspring. Proc Natl Acad Sci USA 1997; 94: 9372-7.

61. Cabanes A, Wang M, Olivo S, DeAssis S, Gustafsson JA, Khan G, Hilakivi-Clarke L. Prepubertal estradiol and genistein exposures up-regulated BRCA1 mRNA and reduce mammary tumorigenesis. Carcinogenesis 2004; 25: 741-8.

62. McCormack VA, dos Santos Silva I, Koupil I, Leon DA, Lithell HO. Birth characteristics and adult cancer incidence: Swedish cohort of over 11,000 men and women. Int J Cancer 2005; 115: 611-7.

63. Ahlgren M, Melbye M, Wohlfahrt J, Sorensen TI. Growth patterns and the risk of breast cancer in women. $N$ Engl J Med 2004; 351: 1619-26.

64. Vatten LJ, Nilsen TI, Tretli S, Trichopoulos D, Romundstad PR. Size at birth and risk of breast cancer: prospective population-based study. Int J Cancer 2005; 114: 461-4.

65. Lahmann PH, Gullberg B, Olsson H, Boeing H, Berglund G, Lissner L. Birth weight is associated with postmenopausal breast cancer risk in Swedish women. Br J Cancer 2004; 91: 1666-8.

66. Kaijser M, Akre O, Cnattingius S, Ekbom A. Preterm birth, birth weight, and subsequent risk of female breast cancer. Br J Cancer 2003; 89: 1664-6.

67. Mellemkjaer L, Olsen ML, Sorensen HT, Thulstrup AM, Olsen J, Olsen JH. Birth weight and risk of earlyonset breast cancer (Denmark). Cancer Causes Control 2003; 14: 61-4.

68. McCormack VA, dos Santos Silva I, De Stavola BL, Mohsen R, Leon DA, Lithell HO. Fetal growth and subsequent risk of breast cancer: results from long term follow up of Swedish cohort. BMJ 2003; 326: 248.

69. Titus-Ernstoff L, Egan KM, Newcomb PA, Ding J, Trentham-Dietz A, Greenberg ER, et al. Early life factors in relation to breast cancer risk in postmenopausal women. Cancer Epidemiol Biomarkers Prev 2002; 11: 207-10.

70. Andersson SW, Bengtsson C, Hallberg L, Lapidus L, Niklasson A, Wallgren A, et al. Cancer risk in Swedish women: the relation to size at birth. Br J Cancer 2001; 84: 1193-8.

71. Hubinette A, Lichtenstein P, Ekbom A, Cnattingius S. Birth characteristics and breast cancer risk: a study among like-sexed twins. Int J Cancer 2001; 91: 248-51.

72. Kaijser M, Lichtenstein P, Granath F, Erlandsson G, Cnattingius S, Ekbom A. In utero exposures and breast cancer: a study of opposite-sexed twins. J Natl Cancer Inst 2001; 93: 60-2.

73. Innes K, Byers T, Schymura M. Birth characteristics and subsequent risk for breast cancer in very young women. Am J Epidemiol 2000; 152: 1121-8.

74. Stavola BL, Hardy R, Kuh D, Silva IS, Wadsworth M, Swerdlow AJ. Birthweight, childhood growth and risk of breast cancer in a British cohort. Br J Cancer 2000; 83: 964-8. 
75. Boland LL, Mink PJ, Bushhouse SA, Folsom AR. Weight and length at birth and risk of early-onset prostate cancer (United States). Cancer Causes Control 2003; 14: 335-8.

76. Ekbom A, Hsieh CC, Lipworth L, Wolk A, Ponten J, Adami HO, et al. Perinatal characteristics in relation to incidence of and mortality from prostate cancer. BMJ 1996; 313: 337-41.

77. Ekbom A, Wuu J, Adami HO, Lu CM, Lagiou P, Trichopoulos D, et al. Duration of gestation and prostate cancer risk in offspring. Cancer Epidemiol Biomarkers Prev 2000; 9: 221-3.

78. Platz EA, Giovannucci E, Rimm EB, Curhan GC, Spiegelman D, Colditz GA, et al. Retrospective analysis of birth weight and prostate cancer in the Health Professionals Follow-up Study. Am J Epidemiol 1998; 147: $1140-4$.

79. Nilsen TI, Romundstad PR, Troisi R, Potischman N, Vatten LJ. Birth size and colorectal cancer risk: a prospective population-based study. Gut 2005; 54: 1728-32.

80. Tibblin G, Eriksson M, Cnattingius S, Ekbom A. High birthweight as a predictor of prostate cancer risk. Epidemiology 1995; 6: 423-4.

81. Ahlgren M, Wohlfahart J, Sørensen TIA, Melbye M. Birth weight and risk of cancer. In: Ahlgren M. Birth weight and growth during school years and risk of cancer. University of Copenhagen, 2004 (PhD Thesis).

82. Bergstrom A, Lindblad P, Wolk A. Birth weight and risk of renal cell cancer. Kidney Int 2001; 59: 1110-3.

83. Leisenring WM, Breslow NE, Evans IE, Beckwith JB, Coppes MJ, Grundy P. Increased birth weights of National Wilms' Tumor Study patients suggest a growth factor excess. Cancer Res 1994; 54: 4680-3.

84. Sandhu MS, Luben R, Day NE, Khaw KT. Self-reported birth weight and subsequent risk of colorectal cancer. Cancer Epidemiol Biomarkers Prev 2002; 11: 935-8.

85. Hjalgrim LL, Westergaard T, Rostgaard K, Schmiegelow K, Melbye M, Hjalgrim H, et al. Birth weight as a risk factor for childhood leukemia: a meta-analysis of 18 epidemiologic studies. Am J Epidemiol 2003; 158: 724-35.

86. Hjalgrim LL, Rostgaard K, Hjalgrim H, Westergaard T, Thomassen H, Forestier E, et al. Birth weight and risk for childhood leukemia in Denmark, Sweden, Norway, and Iceland. J Natl Cancer Inst 2004; 96: 1549-56.

87. Little Jittle: Epidemiology of Childhood Cancer. IARC Scientific Publication No 149, Lyon, 1999.

88. Milner RDG. Mechanisms of overgrowth. In: Sharp F, Fraser RB, Milner RDG, eds. Foetal growth. Proceedings of the $20^{\text {th }}$ study group of the Royal College of Obstetricians and Gynaecologists. London: Royal College of Obstetricians and Gynaecologists, 1989; 139-148. Jun; 15 (5): 517-30.

89. Tretli S. Height and weight in relation to breast cancer morbidity and mortality. A prospective study of 570,000 women in Norway. Int J Cancer 1989; 44: 23-30.

90. Robsahm TE, Tretli S. Height, weight and gastrointestinal cancer: a follow-up study in Norway. Eur J Cancer Prev 1999; 8: 105-13.

91. Thune I, Olsen A, Albrektsen G, Tretli S. Cutaneous malignant melanoma: association with height, weight and body-surface area. A prospective study in Norway. Int J Cancer 1993; 55: 555-61.

92. Tretli S, Magnus K. Height and weight in relation to uterine corpus cancer morbidity and mortality. A followup study of 570,000 women in Norway. Int J Cancer 1990; 46: 165-72.

93. Albanes D, Salbe AD, Levander OA, Taylor PR, Nixon DW, Winick M. The effect of early caloric restriction on colonic cellular growth in rats. Nutr Cancer 1990; 13: 73-80.

94. Albanes D, Taylor PR. International differences in body height and weight and their relationship to cancer incidence. Nutr Cancer 1990; 14: 69-77.

95. Ballen KK, Wilson M, Wuu J, Ceredona AM, Hsieh C, Stewart FM, et al. Bigger is better: maternal and neonatal predictors of hematopoietic potential of umbilical cord blood units. Bone Marrow Transplant 2001; 27: 7-14.

96. Baik I, Becker PS, DeVito WJ, Lagiou P, Ballen K, Quesenberry PJ, et al. Stem cells and prenatal origin of breast cancer. Cancer Causes Control 2004; 15: 517-30.

97. Doll R, Wakeford R. Risk of childhood cancer from fetal irradiation. Br J Radiol 1997; 70: 130-9.

98. Aalen OO, Tretli S. Analyzing incidence of testis cancer by means of a frailty model. Cancer Causes Control 1999; 10: 285-92. 